\title{
The Problem of Domination by Reason and Its Non-Relativistic Solution
}

\section{Abstract}

This paper outlines a solution to what can be called "the problem of domination by reason", "conceptual domination" or "clarificatory injustice". This problem relates to situations where a philosopher may appear to be in a position to legitimately coerce, by means of arguments, an interlocutor, who shares with the philosopher a concept or a conceptual system, to accept a philosophical characterization of a concept or whatever the concept concerns. The proposed solution is based on a particular interpretation of what Wittgenstein means by agreement in his later philosophy, when he says that philosophy only states what anyone grants to it. Wittgenstein's view and the proposed solution are characterized by their continued recognition of the value of logic and reason, truth and knowledge, as opposed to attempting to solve the problem by embracing relativism and questioning the value of the logic, reason, truth and knowledge. Relevant kind of disagreements licence no relativistic conclusions, because problems relating to them can be solved without going this far.

\section{The problem of injustice and domination by reason}

One of the most common claims made by philosophers is that they will (intend or want to) clarify something. A much more contested issue is whether and how often they actually manage to clarify what they set out to clarify, either to themselves or others. In connection with such 
clarifications, or attempts to clarify, a problem arises which we might call "the problem of domination by reason", "the problem of conceptual domination" or "the problem of clarificatory injustice". The problem can be described as follows. Assuming that the philosopher and her interlocutor share a common system of concepts or that they both partake in reason, the philosopher seems to be sometimes in a position, due to her more advanced capacity or skill to clarify those shared concepts or principles of reason, to coerce or force, by means of arguments, the interlocutor to accept against her will philosophical clarifications (for example, conceptual definitions). Problematically, nothing seems to exclude the possibility that in such a case the interlocutor would be wrongly made to accept a merely alleged clarification that does not really reflect her concepts or thinking, but distorts them. Thus, the philosopher might end up, regardless of good and honest intentions, doing injustice to the interlocutor's thinking. ${ }^{1}$

This problem of injustice and domination by reason arises especially in the context of conceptions of philosophy which assume that the philosopher's task is to articulate universal or exceptionless theses of essence (concerning the non-accidental features of the objects of investigation) or universally or exceptionlessly valid conceptual determinations that cover all instances falling under a concept. Here an important tacit assumption is made about conceptual unity or the unity of cases sharing an essence, according to which it is always possible to give an overarching definition or determination of a concept or essence in terms of features common to all cases falling under the concept that covers all possible instances of the concept's application. However, this assumption is problematic in that, insofar as it is not part of the concept of concept that concepts necessarily possess this kind of simple unity, agreement between the philosopher and the interlocutor on a conceptual clarification regarding some cases

\footnotetext{
${ }^{1}$ Throughout this discussion I will assume that the philosopher, in giving such arguments, is engaged in what might be called "immanent critique" of the interlocutor's concepts or language use. She is not trying to impose on the interlocutor a system of concepts or beliefs that the interlocutor does not already share with her, but the problem concerns the misrepresentation of those shared concepts. The philosopher's argument is therefore assumed to be nondogmatic in the sense of Kant, proceeding from within shared concepts or principles of reason, and not relying on anything to which the interlocutor is not already committed. For Kant's notion of dogmatism and Wittgenstein's broader notion of the same, see Kuusela 2008 and 2008a.
} 
falling under a concept does not automatically imply an agreement regarding other cases falling under the same concept. But evidently, simple conceptual unity is not a necessary feature of concepts, as shown by there being no contradiction in the description of other more complex modes of conceptual unity.

I give three examples for illustration. 1) Wittgenstein's account of family-resemblance concepts, whereby conceptual unity is determined through criss-crossing similarities. Schematically, this allows two different kind of cases to fall under the same concept, despite their not sharing any features, as long as they share features with a third kind of case that unites the two cases as an intermediary (PI: \65ff.). 2) Concepts expressed by what J. L. Austin calls "dimension-words", characteristic of which is that they have multiple different opposites. Austin example is "real" whose contrasts include "fake", "artificial", "copy", "makeshift", "imaginary", and so on, and which can be taken to mean something different depending on what it is contrasted with (Austin 1962: 71). 3) Nietzsche's genealogical account of morality as a multi-layered construct, whereby the concepts of good and evil reflect their complex history of formation, and incorporate different, even incompatible elements and considerations that derive from what Nietzsche describes as the morality of the nobles and slaves (Nietzsche 2008). Given the possibility of this kind of conceptual complexity, philosophical clarification can readily fail to do justice to the thinking and concepts of the philosopher's interlocutor, insofar as such clarifications assume simple conceptual unity, but the interlocutor's concepts possess a more complex unity. Evidently, agreement about how to characterize or define a certain type of case that falls under a particular concept does not here guarantee the applicability of the same characterization or definition to other cases falling under the same concept.

I agree that the feeling of injustice being done to one's thinking or concepts can accurately reflect the situation. Given the possibility of preceding kind of conceptual complexity, clarificatory injustice in the sense of conceptual domination or domination by reason can readily occur. Problematically, however, the possibility of this kind of clarificatory injustice seems to have led to responses in certain quarters of philosophy and cultural studies that put into question the value of 
the notions of reason, logic, knowledge and truth, which are consequently regarded as instruments of domination and oppression rather than as necessary for emancipation and liberation in the sense in which both ancient and enlightenment philosophy have regarded them as necessary for freedom. Sometimes this may have led to the acceptance of relativism, and sacrificing the notions knowledge, truth, and/or logic, perhaps thus pushing us towards something like an era of post-truth, whatever that would mean. Arguably, however, such a response is problematic - an unnecessary overkill. To be sure, if there is no objective truth or knowledge and no principles of reason or logic, then the philosopher cannot tell others what the objective truth is and what the principles governing reason are, or force them to accept and comply with the philosopher's an account of such things. However, overthrowing the notions of truth, knowledge, reason and logic seems an unacceptably high price to pay for solving the problem of domination by reason, conceptual domination or clarificatory injustice. ${ }^{2} \mathrm{I}$ am inclined to think that this response merely constitutes a tempting confusion, although I will not try to argue so. Nevertheless, one may certainly wonder whether justice and freedom are possible at all without truth, knowledge, reason and logic. (Is it possible to be free without a correct understanding of one's situation?) I would therefore like to outline a different solution to the problem.

As I will explain, there is a way to construe Wittgenstein's notion of agreement in philosophy that can solve the problem of domination by reason and clarificatory injustice without our being forced to abandon reason, logic, knowledge and truth, and without our being led to relativism or to deny the value of reason, logic and truth. On the proposed interpretation of the notion of agreement in Wittgenstein's philosophy, philosophy can involve no attempt to try to force anyone to accept anything.

\footnotetext{
${ }^{2}$ It may be that the kind of relativism imagined here is merely a popular post-modern fiction or a creature of university politics in the US. There are rumours of philosophers holding such a view, but I have yet to identify any serious philosopher who would do so. Ultimately nothing depends on this, however. The problem of domination by reason and clarificatory injustice is real, and calls for a solution. For varieties of relativism, see Haack 1998 and Hales 2011.
} 


\section{The Wittgensteinian solution}

According to Wittgenstein (PI: \599), "Philosophy only states what everyone grants to it." Various readings of this remark have been offered, including a reading by Anthony Kenny according to which Wittgenstein's claim cannot be taken seriously in that the only thing that can be agreed upon in Wittgenstein's writings are uninteresting trivialities, while anything of philosophical interest is controversial (Kenny 2004). According to a somewhat different interpretation put forward by Hans-Johann Glock, and agreed upon by Peter Hacker and the influential scholar-duo Baker and Hacker (see below), Wittgenstein's remark is to be read as stating that there is something, namely Wittgensteinian grammatical rules or statements thereof that philosophy spells out, and which everyone who participates in and shares certain linguistic or conceptual practices must grant to it and accept. As Glock explains, "we should expect" "a universal assent" to such grammatical statements (Glock 1991: 79).

It is notable how this account that the philosopher is able to tell her interlocutors what they must accept or otherwise suffer irrationality exhibits certain key features of the very view of the philosopher's role that raises the problem of domination and injustice. Analogously to the traditional philosopher's comprehension of essences or shared principles of reason, for Glock it is the philosopher's superior understanding of grammatical rules and statements that puts her in the position of intellectual power. Once such a rule is agreed upon at some point of a discussion as capturing the interlocutor's use of relevant linguistic locutions, the philosopher is, according to this view, licensed to apply it also to further cases that may arise without having to consult the interlocutor, thus being able to demonstrate to the interlocutor that what she is saying is inconsistent or makes no sense. As Glock explains, "the special function of grammatical reminders is to draw attention to the violation of linguistic rules by philosophers, a violation that results in nonsense" (Glock 1991: 78; original italics).

It may be granted that mere deviance from ordinary linguistic practice does not constitute a philosophical mistake. But the idea is to demonstrate a certain kind of inconsistency in the philosophical positions or questions attacked, an inconsistency concerning the uses of words (Glock 1991: 84; original italics). 
In this way we can construe arguments which "philosophers will have to accept" (Glock 1991: 86).

But if language and our concepts are complex enough not to fit neatly any such systems of rules that we might spell out with the purpose of clarification, as Wittgenstein arguably maintains (PI: $\iint 81-$ 83), a philosopher with Glock's approach seems to be at risk of doing injustice to her interlocutors. For clearly, in inferring from the interlocutor's agreement at a certain juncture of a discussion that she uses language according to such and such rules to the allegedly necessary-to-accept conclusion that she has fallen into nonsense or inconsistency at some other point, Glock is assuming that the Wittgensteinian philosopher is able to establish some definite set of rules which the interlocutor must stick to so as to speak sense. Otherwise the interlocutor could conceivably sometimes respond, "Yes, those rules that I agree on apply here, but not there, in these further cases", and the damning conclusion would not be necessary to accept, after all. Similarly to Glock, also Baker and Hacker maintain that it is not possible to disagree with the philosopher's statement of a grammatical rule. Whoever disagrees is either failing to make sense or is using their words in a new meaning which is irrelevant to the philosophical issue under discussion (Baker and Hacker 1980: 490491; cf. Hacker 2001: 333, 335). The problem of domination by reason and clarificatory injustice therefore also arises in connection with certain well-established Wittgenstein-interpretations.

But there is an alternative to the preceding readings of Wittgenstein that can solve the problem. Perhaps the most crucial difference between the mentioned readings and this alternative is that, rather than construing grammatical rules as the object or target of philosophical clarification and statements, as Glock, (Baker and) Hacker and Kenny all do, this interpretation regards grammatical rules and statements as instruments of philosophical clarification or as clarificatory devices. On this account, Wittgensteinian philosophical statements are not statements of grammatical truths or facts regarding the rules which allegedly govern our use of language and concepts, and which speakers or the users of the concepts in question could be forced to agree with. Instead, grammatical rules and statements are instruments by means of which complex conceptual relations or logical possibilities and 
necessities can be clarified, without claiming that such rules or statements capture those relations, possibilities and necessities exactly as they are. Hence, Wittgensteinian grammatical rules or statements, and other philosophical models or modes of representation (such as simple language-games or what might be called "natural historical pictures"; see Kuusela 2019 for discussion) may simplify and idealize. Instead of being claimed to capture the use of relevant words exactly as it is, whereby they would account for all cases falling under relevant concepts without exception, as traditional philosophical theses are intended to do, such clarifications are intended to bring into focus specific aspects of our concepts, with a view to addressing particular philosophical problems.

With regard to the possibility of idealization without falsification it is important that Wittgenstein rejects as confused the abstract notion of the completeness of clarifications, according to which a philosophical clarification should contain an answer to every possible problem or unclarity that might arise about a concept or issue under examination. Since new problems can always be raised and imagined, this criterion of the completeness of clarifications is in principle impossible to satisfy (AWL, 21; TS 220, \$114/Z \440; cf. MS 115, 5052). Instead, a clarification "only" needs to be able to clarify whatever is relevant for the resolution of the particular philosophical problems that are discussed, whereby what counts as relevant is determined with reference to the problems in question or whatever is at stake in the discussion. A clarification is then complete, when it clarifies whatever is relevant from the point of view of resolving the problems in question. Accordingly, insofar as a clarification captures what is relevant for the discussion, it is not problematic for it to simplify and idealize, for example, to present as sharp a distinction that is only unclearly indicated in the use of natural language or in everyday speech (PI: \$77). As long as an idealized grammatical model captures whatever is relevant for the discussion at hand, it does not falsify anything in that context.

Provided this sketch of an alternative to Glock's, Baker and Hacker's and Kenny's interpretations of the logical role or function of grammatical statements, let us now turn to how this account of grammatical statements as instruments of clarification enables us to 
explain the notion of agreement in Wittgenstein very differently from Glock and (Baker and) Hacker, and how this helps to solve the problem of domination by reason and clarificatory injustice. As I hope to make clear, this reading can bring down to earth Wittgenstein's very difficult to understand statement that philosophy only states what everyone grants to it, rendering it both comprehensible and sensible (PI: \599).

\section{Wittgenstein on agreement in philosophy}

Wittgenstein's view of agreement in philosophy is intended to take seriously the task of philosophy as clarification. This precludes the clarifier from assuming that what she finds problematic about an issue is exactly the same as what the interlocutor finds problematic, and therefore that a clarification that clarifies matters to the clarifier herself should necessarily clarify them to the interlocutor too. Rather, what exactly is the problem, and what helps to solve it, is something to be worked out in a discussion and agreed upon. (Of course, this does not exclude the possibility of sharing problems or that a clarification that helps one person could help another one.) This has the consequence that something not agreed upon does not qualify as a philosophical, clarificatory statement. Rather, what counts as clarification is defined by its clarificatory effect. As Wittgenstein explains: "An explanation of words has clarificatory value for the person to whom it clarifies something, upon whom it has a clarifying effect. Independently of that it is not an explanation" (MS 123: 18r; from 1940). According to Wittgenstein, therefore, a statement qualifies as a clarification only insofar as it actually clarifies something; a clarification is something that succeeds as a clarification. What does not clarify, despite intentions to do so, is only an attempt at clarification. Relatedly, Wittgenstein comments on the difference between his way of philosophizing and other philosophers: "The difference between my philosophizing and that of others is really: what I write down as preparation for philosophical clarification they regard as a philosophical clarification" (MS 136: 41b; from 1948; original italics/underlining). Clarifications, as the point can be explained, cannot be passively received. Clarification requires that the interlocutor thinks for herself, that she works with the clarification in order to see how (and whether) what is offered as a clarification 
actually clarifies matters, and that she comes to agree with the clarification on this basis. A clarification cannot be imposed on anyone, and still qualify as a clarification.

This view of what counts as a clarificatory and a philosophical statement then entails that in philosophy the very possibility is excluded of putting forward theses, in the sense of controversial true/false statements to be debated. As Wittgenstein writes in another remark on agreement in the Investigations: "If one tried to advance theses in philosophy, it would never be possible to debate them, because everyone would agree to them" (PI: \$128/Ms110: 259; cf. WVC: 183). In other words, insofar as a philosophical clarification is something agreed upon as successfully clarifying something, theses in the sense of controversial true/false statements do not qualify as philosophy. Accordingly, as Wittgenstein remarks in the same manuscript where Investigations $\$ 128$ is first drafted: "only when I say what is self-evident is it philosophy" (Ms110: 214 /Ts211:256, from 1931; cf. Ms136: 41b). Numerous statements can also be found in Wittgenstein's lectures according to which he is willing put to the side anything not be agreed upon. For instance: "I won't say anything that anyone can dispute. Or if anyone does dispute it, I will let that point drop and pass on to say something else" (LFM: 22; see 55, 102, 103; AWL: 97).

Wittgenstein therefore clearly does not intend to make his interlocutor accept anything she does not want to accept. But can one really take seriously the claim that he would drop any point not agreed upon? I believe one can, but only if grammatical rules and statements thereof are clearly distinguished from philosophical or grammatical theses and understood as instruments or devices of clarification. As long as grammatical statements are conceived according to the model of statements of "grammatical truths" regarding the rules of language, comparable to philosophical theses as the statement of truths about necessities, the feeling is bound to persist that Wittgenstein's statement about dropping anything not agreed upon is merely rhetorical and ultimately dishonest. Secretly he knows that insofar as the interlocutor uses, for example, the word "meaning" in the normal way, she will have 
to acknowledge the rule "meaning is use" as the description of the word's use. We should expect a universal assent, as Glock says. ${ }^{3}$

Let me briefly illustrate the difficulty that arises for a view like Glock's and (Baker and) Hacker's of making consistent sense of Wittgenstein's view. Similarly to Glock, Hacker writes about clarificatory accounts proposed by Wittgenstein, such as the conception of an inner mental process as standing in need of outer criteria and the conception of mathematical propositions as rules:

If challenged, they can be withdrawn, and painstaking description of the use of words resumed until it becomes clear that the way we use psychological predicates in the third person involves behavioural criteria for their application, and that the characteristic employment of mathematical propositions is normative (Hacker 2001: 334).

According to this account, the end result, or what will be agreed upon, is already known to the philosopher in advance of the clarificatory discussion and investigation of the matter together with the interlocutor. The discussion will be resumed until agreement about the grammatical clarifications has been reached (or clarification is given up as futile). But the contrast with Wittgenstein could hardly be starker when he says: "I have no right to want you to say that mathematical propositions are rules of grammar" (LFM: 55). Wittgenstein does indeed propose that the matter be investigated, and this is important. As explained a clarification cannot be passively accepted; the interlocutor must recognize that it actually clarifies. Unlike Hacker, however, Wittgenstein carefully avoids suggesting that the outcome is already decided. As the quote evinces, he denies himself the right to want a specific outcome. ${ }^{4}$

\footnotetext{
${ }^{3}$ That the logical function of grammatical statements cannot be understood on the model of true theses does not mean that one cannot speak about the truth or correctness of clarifications. It only means that their truth or correctness is not to be thought of in terms of correspondence with any "grammatical facts" relating to linguistic rules or necessities and possibilities concerning language use. For the notion of truth or correctness of clarifications, see Kuusela 2019, Chapters 2.3, 3.7, 6.1 and 6.6.

${ }^{4}$ In this connection, Wittgenstein's exact wording in PI: $\$ 599$ is important. As Kenny points out (2004: 173), according to Wittgenstein philosophy only says what everyone agrees upon, not what everyone should agree upon, as Glock and Hacker maintain. This is an important observation, but as indicated earlier, Kenny's interpretation does not seem able to explain Wittgenstein's view.
} 
The suspicion that Wittgenstein cannot really mean that he would give up his statements about grammar is dissipated as soon as such statements are understood as instruments or devices of clarification. This adjustment - which amounts to swapping one picture of the role of grammatical or philosophical statements for another - transforms the whole situation. Crucially, from the point of view according to which grammatical rules or models constitute instruments of clarification, dropping a statement not agreed upon does not emerge as equivalent to abandoning an important "grammatical truth". Rather, this is analogous to exchanging one tool for another more suitable for a task at hand. When viewed in the light of this picture, Wittgenstein's readiness to drop any grammatical remarks not agreed upon begins to sound not only comprehensible, but sensible, as can now be outlined.

Which clarificatory statements or accounts one can or must employ in tackling a problem depends on what exactly those to whom the clarification is offered find problematic about the issue. This means that in some cases one might not be able to employ certain clarificatory statements or accounts because the participants in the discussion find those statements problematic. (This kind of variation can be found between philosophy departments, for example, with one set of assumptions accepted in one department but not another.) In such a case, the clarifier has to find other means to address the issue at hand. Hence, as this illustrates, in selecting the right instruments for clarification one must also take into account the interlocutors' intellectual backgrounds, i.e., the philosophical convictions that provide a background for the problem(s) at hand, and constitute a context in which it is (they are) to be resolved. Now a readiness to drop clarificatory statements, if they are not agreed upon, then emerges as a readiness to respond to a clarificatory task as required by its specific circumstances. It does not amount to holding no views about grammar or philosophical questions. But it is not a matter of overconfidence about others having to come to acknowledge certain clarifications of grammar either. These are both false options. (Glock 1991 rejects the first option and embraces the second one.)

Indeed, the outlined view is perfectly compatible with realism in philosophy, i.e. the view that things are as they are quite independently of us, and that there is such a thing as truth and getting things or 
grammar right or wrong. As Wittgenstein himself notes about realism as a philosophical aim, "Not empiricism and yet realism in philosophy, that is the hardest thing" (RFM VI: \$23/MS 164: 67). To be sure, Wittgenstein's non-empiricist realism is not a version of naïve realism where we, so to speak, read out of our objects of investigation how we should conceptualize and think about them. Our concepts do not simply reflect reality but they are also expressions of our interests and concerns, as Wittgenstein notes. "Concepts lead us to make investigations; are the expression of our interest and direct our interest" (PI: \$570).

The relevant point for the present discussion is that, as regards philosophical methodology, we are not entitled to assume that reality is as simple as our theses or models of it represent is as being. Reality may be more complex than our representations, as the problems relating to the philosophers' assumption of simple conceptual unity show (cf. section 1). Consequently, we ought not to expect - naïvely or arrogantly - that reality will neatly conform to our philosophical accounts, or claim that such accounts show how things must be in reality in the sense which a philosophical thesis claims to capture a necessity pertaining to reality. However, to emphasize, what is at stake here is not an ontological thesis about the inexhaustible complexity of reality, i.e. claim about the nature of reality as more complex than our models can account for. This would contradict the view spelt out here, and smuggle in a philosophical thesis about the nature of reality. Instead, the point is merely methodological and negative, relating to the philosophers' problematic habit of imposing philosophical models onto reality or language use in the form of claims about how things must be. Such claims involve running together a philosophical model and its object, whereby a necessity characteristic and constitutive of a philosophical model is confused with a necessity found in reality or in actual language use (PI: $\$ \$ 104,114$; see Kuusela 2019, Chapters 4.44.5 for discussion).

Instead, as Wittgenstein explains, philosophical models in terms of which we seek to clarify our concepts, or whatever those concepts speak about, are better seen as "objects of comparison". They are models or modes of representation with which reality is compared, not only for similarity but also for how it differs from our models. (Note 
how this highlights the instrumental character of the models.) In other words, we ought to see our philosophical accounts as modes of representing reality by means of which we seek to render it comprehensible, and in terms of which we seek to order or organize it for the purpose of clarification. But we should not forget what our models are. They are just that, models developed by us with the purpose of understanding how things are. Accordingly, the logically perspicuous order we seek to bring about is not the order, an ultimate metaphysical or logical order of things or language use, as Wittgenstein emphasizes (PI: $\$ \$ 122,130-132)$. Here we must be careful, as he keeps warning, not to falsify reality by means of our models. A philosophical model " $[. .$.$] is supposed to be a picture with which we compare reality,$ through which we represent how things are. Not a picture by which we falsify reality" (MS 183: 163-164/PPO 97; from 1937; see Kuusela 2008a: 121-122 for further discussion of this quote). We run the risk of falsifying reality, however, if we expect that our objects of investigation, including the rules according to which language is used, should neatly correspond to our models, and project those models onto reality, or onto our interlocutors' thinking, in the capacity of claims or theses about the rules governing her language use. ${ }^{5}$

\section{The problem of domination and injustice: What is one expected to agree upon?}

I hope the preceding makes clear how the problem of conceptual domination, domination by reason or clarificatory injustice can be solved without denying the value of reason or logic, and without sacrificing the notions of knowledge and truth in the sense in which some forms of relativism might sacrifice them. Since a clarification must be agreed to actually clarify, it is not possible to force someone to accept a clarification. Naturally, this does not mean that arguments could not play an important role in clarification. They can, for example,

\footnotetext{
5 "Reality" is meant to refer here to both, the phenomena of reality as well as the concepts in terms of which we speak about those phenomena, whenever the latter are taken as the objects of clarification. In the capacity of objects of clarification/investigation, our concepts, or the uses of language in which they find their expression, constitute a part of reality as opposed to the modes of representation in terms of which we seek to clarify them. The distinction between an object and means of representation is relative and dynamic (not absolute and static) in this sense.
} 
be used to clarify the consequences or presuppositions of a view. However, that they have successfully done so is still subject to agreement which might be granted or refused. Arguments, and the examination of logical presuppositions and consequences does not somehow take us beyond the need to agree on clarifications.

I hope it is now also clear how the outlined account of Wittgenstein's clarificatory practice manages to bring down to earth the notion of agreement in his philosophy. According to the proposed interpretation, his claim is not, pace Glock and (Baker and) Hacker, that there are remarkable kind of statements that everyone who adheres to a certain practices of language use must agree upon on pain of irrationality. It is not, in this sense, of the essence of grammatical statements that they will - eventually, necessarily - be recognized and agreed upon by all rational beings or language users equipped with relevant concepts. Indeed, since neither Wittgenstein nor any Wittgensteinians have actually produced any statements that are both readily recognizable as philosophical and agreed upon by everyone (cf. Kenny's point), it is hard to see why the idea that there must be such statements should not be characterized as a theoretical postulate of certain Wittgensteinians, such as the mentioned scholars. Indeed, as far as postulates go, this one certainly seems controversial and implausible, given the almost seventy years since the publication of the Philosophical Investigations that Wittgensteinians have had to come up with grammatical statements agreed upon by philosophers and other language users generally. I see no essential difference between the fact of disagreement about Wittgensteinian grammatical statements and about traditional philosophical theses; Wittgensteinians do not seem to have been more successful than philosophers traditionally in forcing others to agree with their statements. ${ }^{6}$

Instead of postulating such extraordinary statements that interlocutors will have to agree with, we can simply maintain that to agree on a grammatical statement is to agree in the context of some specific discussion or discussions that the philosopher's clarificatory statement is capable of clarifying some aspect of the matter at hand to

\footnotetext{
${ }^{6}$ For discussion of Wittgenstein and the issue of disagreement in philosophy with regard to the question of what might explain persistent disagreement in philosophy, and why disagreement would be better acknowledged as part of philosophy rather than gotten rid of, see Kuusela 2017.
} 
some extent. Thus, one is not expected to accept grammatical statements in the abstract, without reference to specific clarificatory goals. Clarifications are only offered in response to particular actual problems or unclarities, and this is the context in which they can be agreed upon or rejected. Importantly, this also makes grammatical clarifications much easier to agree upon than is the case from the point of view of Glock's and (Baker and) Hacker's account. What one is asked to agree upon is not a statement concerning a definitive grammatical order, an order that must be recognized as underlying language use. (Such a definitive order is not what Wittgenstein means by "perspicuous (re)presentation"; see PI \$122 and Kuusela 2008: 228ff. for discussion.) Instead, agreement only constitutes an acknowledgement that a clarification has succeeded in clarifying certain specific issues under discussion, while it is left open that other clarificatory models might be needed in the context of the discussion of other problems relating to the same concepts or cases, or when we turn our attention to other cases that fall under the same concepts. By way of quick illustration, although Wittgenstein's conception of language as a game according to rules may be helpful in clarifying certain aspects of the concept of linguistic meaning, it does not seem very helpful with regard to certain other issues relating to linguistic meaning, such as the relevance of sound for meaning in the case of poetic language use. Here associations relating to sounds play a role, unlike in cases where meaning depends on rules for use. But insofar as meaning depends on rules, the sound of words is irrelevant for their meaning (cf. AWL: 104; for further discussion, see Kuusela 2019, Chapter 6.5).

Accordingly, it is misleading to conceive grammatical statements as stating "grammatical truths" that must be recognized on pain of irrationality by all users of those concepts, as suggested by Glock's and (Baker and) Hacker's picture of the necessary acceptance of grammatical statements on pain of irrationality. As argued, grammatical statements are instruments employed to resolve particular philosophical problems and unclarities in particular historical contexts. Since what needs to be said about a philosophical issue is whatever is relevant for resolving the particular problems and unclarities that one is concerned with, and different things may be relevant from the point 
of view of different problems relating to one and the same object of investigation, different things might be said about an object of investigation in different contexts of discussion. But this does not mean that just anything could be helpfully said. Nor does it mean that there is not a way that things are, as if the facts pertaining to reality or language use depended on those who seek to clarify them, on what we find problematic or interesting. Wittgensteinian pluralism of clarifications is therefore compatible with knowledge and truth and there being an objective independent reality. Accordingly, the view is clearly distinguished from relativism in the sense of a thesis that denies the possibility of knowledge, truth, logic, and objectivity.

\section{Who is clarifying what to whom?}

Let me now raise a question about the authority of a philosopher as a clarifier. Does the philosopher occupy here some kind of authoritative position as opposed to the interlocutor? As I have argued, the proposed interpretation of the concept of agreement in Wittgenstein's philosophy can successfully remove a certain air of implausibility or disingenuousness that surrounds his remarks about agreement on the interpretations of Glock and (Baker and) Hacker. Nevertheless, it is important that the preceding description of the practice of clarification remains idealized in certain respects. Rather than revealing a problem with Wittgenstein's conception of philosophy or with the proposed interpretation of it, however, this is indicative of the logical status of the proposed account.

It is not true that in real life the roles of the participants in a philosophical discussion would be as neatly delineated as portrayed above. In actuality the roles of philosopher and interlocutor in the sense of the provider and recipient of clarifications respectively can rarely be identified with specific participants in a discussion. Indeed, if the participants in the discussion are to learn from one another, and the relation between them is not a one-directional relation of instruction, their roles cannot be assumed to be fixed in this way. It is crucial, then, that the preceding depiction is not intended as an empirically accurate factual description. Rather, it constitutes a simplified model which is itself to be used as an object of comparison in accordance with Wittgenstein's philosophical methodology. The 
purpose of the model is to spell out a way of conceiving philosophical discussion and the participants' roles in it, and to introduce in this way order and perspicuity into the actual blurred reality of philosophical discourse, where the participants in a discussion may actually occupy either the role of the philosopher or interlocutor, and switch between these roles.

The point of conceiving philosophical discussion in this way is that it solves certain problems relating to the philosopher's role, in particular the problem of domination by reason and the philosopher doing injustice to the interlocutor by imposing views on her as something she allegedly must accept. As Wittgenstein also says about the task of philosophy: "Our only task is to be just. That is, we must only point out and resolve the injustices of philosophy, and not posit new parties-and creeds" (TS 213: 420/PO: 181; cf. PI: \$131). It is plausible that he is referring here to philosophical parties as defined by their theses about how things must be, concerning the necessary features of our objects of investigation. He himself, on the other hand does not trade in such theses, but merely employs philosophical definitions, grammatical rules and other models as instruments of clarification. Consequently, because it is characteristic of Wittgenstein's use of relevant kinds of models that they can be withdrawn if not agreed upon, there is no need to insist on any statements of grammar in the context of Wittgenstein's approach. With the disappearance of the need to insist on the acceptance of any clarifications, the problem of injustice also disappears. In this sense the requirement of agreement is to be regarded as part of Wittgenstein's design for a method that can dissolve the problem of injustice in philosophy. ${ }^{7}$

Another sense in which Wittgenstein's conception of the status of philosophical remarks is idealized is the following. If one interprets his remark, that only what is agreed upon or self-evident qualifies as a philosophical statement, as a thesis about what a philosophical statement must be or is by nature, very little of what is said when philosophy is actually practiced qualifies as philosophical. More often than not philosophers disagree. Wittgenstein's statement, therefore,

\footnotetext{
7 Of course, an interlocutor may falsely accept a wrong characterization of her concepts or what those concepts concern. But this is no longer a matter of a philosopher doing injustice to her views. Here the interlocutor is misconstruing them herself, and ultimately nothing excludes the possibility of finite beings falling into such errors.
} 
seems to express a very strict view of philosophy unable to accommodate what most philosophers would regard as "philosophical statements". However, this problem disappears, just like the problem of the empirical inaccuracy of his characterization of the philosopher's and the interlocutor's roles, when the statement is understood as articulating a philosophical model to be used as an object of comparison. This means that the view of philosophical statements as self-evident and agreed upon does not constitute a thesis to which every legitimate philosophical statement must conform. Rather, it is a defining characteristic of Wittgenstein's account of philosophy, a principle according to which the activity of clarification is to be carried out. In philosophical clarification agreement must be sought, and only what actually clarifies ultimately counts as a clarification, as opposed to attempted clarifications. This is what clarifications are on the model in the light of which Wittgenstein proposes to understand the discipline of philosophy. The justification of this model of philosophy, in turn, depends on the philosophical work it can do, i.e. on the problems it can solve, such as the problem of domination by reason, conceptual domination or clarificatory injustice - or the problem of dogmatism or of the justification of philosophical statements (see Kuusela 2008a and 2019). Thus, Wittgenstein's account of the logical role of philosophical statements as something that need to be agreed upon is neither a thesis about the nature of philosophical statements nor an arbitrary stipulation.

In this connection it is noteworthy that according to Wittgenstein, the activity of clarification or philosophy consists not only of making statements but also, for instance, of asking questions. As he remarks:

In philosophy it is always good to put a question instead of an answer to a question. For an answer to the philosophical question may easily be unjust; disposing of it by means of another question is not. (MS 122: 14r/RFM: 147; cf. AWL: 97f.)

If agreement is interpreted as a requirement that everything we say in philosophy must satisfy, asking questions would not qualify as philosophizing. Or at most, rhetorical questions would qualify. This supports the view that Wittgenstein does not intend the requirement of agreement as a thesis that everything said in philosophy must meet, a highly controversial and implausible claim in itself. This thesis would 
give rise to contradictions in Wittgenstein's account of philosophy that are too obvious to attribute to him.

\section{References}

Austin, J. L., 1962. Sense and Sensibilia. Oxford: Oxford University Press. Baker, G. and Hacker, P. M. S., 1980. Wittgenstein, Understanding and Meaning: An Analytical Commentary on the Philosophical Investigations. Oxford: Basil Blackwell.

Glock, H.-J., 1991. "Philosophical Investigations Section 128: 'Theses in Philosophy' and Undogmatic Procedure". In: R. L. Arrington and H.-J. Glock, eds., Wittgenstein's Philosophical Investigations, Text and Context. London: Routledge, 69-88.

Haack, S., 1998. "Reflections on Relativism: From Momentous Tautology to Seductive Contradiction". In: S. Haack, Manifesto of a Passionate Moderate: Unfashionable Essays. Chicago: Chicago University Press, 149-166.

Hacker, P., 2001. "Philosophy". In: H.-J. Glock, ed., Wittgenstein: A Critical Reader. Oxford: Blackwell, 322-347.

Hales, S., ed., 2011. A Companion to Relativism. Oxford: Wiley-Blackwell. Kenny, A., 2004. “"Philosophy States Only What Everyone Admits"'. In: E. Ammereller and E. Fischer, eds., Wittgenstein at Work: Method in the Philosophical Investigations. London and New York: Routledge, 173182.

Kuusela, O., 2008. "Transcendental Arguments and the Problem of Dogmatism". International Journal of Philosophical Studies 16 (1), 57-75.

Kuusela, O., 2008a. The Struggle against Dogmatism: Wittgenstein and the Concept of Philosophy. Cambridge, MA: Harvard University Press.

Kuusela, O., 2017. "Wittgenstein's Comparison between Philosophy, Aesthetics and Ethics". In: S. Majetschak and A. Weiberg, eds., Aesthetics Today: Proceedings of the $39^{\text {th }}$ International Ludwig Wittgenstein-Symposium in Kirchberg, 2016. Offenbach: Ontos, 333-348.

Kuusela, O., 2019. Wittgenstein on Logic as the Method of Philosophy: Re-examining the Roots and Development of Analytic Philosophy. Oxford: Oxford University Press.

Nietzsche, F., 2008. On the Genealogy of Morals. Oxford: Oxford University Press.

Waismann, F., 1979. Wittgenstein and the Vienna Circle, Conversations Recorded by

Friedrich Waismann. B. McGuinness, ed. Oxford: Blackwell. (WVC)

Wittgenstein, L., 1967. Zettel. G.E.M. Anscombe and G.H. von Wright, eds.

Oxford: Basil Blackwell. (Z)

Wittgenstein, L., 1976. Lectures on the Foundations of Mathematics, Cambridge 1939.

C. Diamond, ed. Hassock, Sussex: Harvester Press. (LFM) 
Wittgenstein, L., 1979. Wittgenstein's Lectures, Cambridge 1932-35. A. Ambrose, ed. Oxford: Basil Blackwell. (AWL)

Wittgenstein, L., 1993. Philosophical Occasions 1912-1951. J. Klagge and A.

Nordmann, eds. Indianapolis: Hackett. (PO)

Wittgenstein, L., 1997. Philosophical Investigations, $2^{\text {nd }}$ ed., G.E.M. Anscombe and

R. Rhees, eds. Oxford: Blackwell Publishers. (PI)

Wittgenstein, L., 1998. Remarks on the Foundations of Mathematics. G.E.M.

Anscombe, R. Rhees and G.H. von Wright, eds. Oxford: Basil Blackwell.

(RFM)

Wittgenstein, L., 2000. Wittgenstein's Nachlass: The Bergen Electronic Edition. The

Wittgenstein Archives at the University of Bergen, eds. Oxford: Oxford University Press.

\section{Biographical Note}

Oskari Kuusela is Senior Lecturer in Philosophy at the University of East Anglia. He is the author of The Struggle Against Dogmatism: Wittgenstein and the Concept of Philosophy (Harvard University Press, 2008), Key Terms in Ethics (Continuum/Bloomsbury, 2010) and Wittgenstein on Logic as the Method of Philosophy: Re-examining the Roots and Development of Analytic Philosophy (Oxford University Press, 2019). He is the co-editor of Wittgenstein and His Interpreters (Blackwell-Wiley, 2007, paperback 2013), The Oxford Handbook of Wittgenstein (Oxford University Press, 2011, paperback 2014), Wittgenstein and Phenomenology (Routledge, 2018), and Ethics in the Wake of Wittgenstein (Routledge, 2019). 